\title{
«No somos nadie sin el otro»: autenticidad y ciudadanía al interior de una comunidad transnacional de «resurgentistas» de la música andina*
}

\section{Daniel Castelblanco}

https://orcid.org/0000-0003-1704-3616

Universidad de Elon, Estados Unidos

dac98@georgetown.edu

\section{RESUMEN}

A partir de la década de 1970, ciudades latinoamericanas como Lima, La Paz, Buenos Aires, Santiago y Bogotá han atestiguado el surgimiento y desarrollo de escenas musicales basadas la interpretación colectiva de las flautas de Pan conocidas con el nombre aimara de sikus - instrumentos originalmente interpretados por agricultores indigenas en los Andes centrales. Aunque la mayoría de quienes participan en estas escenas no crecieron en contextos en que la interpretación de sikus formara parte de un traspaso generacional, hoy asumen esta práctica como propia y le confieren usos y significados funcionales a sus propios entornos y agendas. Con base en numerosas jornadas de trabajo de campo multisituado al interior de las escenas sikuri de Buenos Aires, Santiago y Bogotá, en este artículo argumento que su creciente interconexión ha dado forma a un movimiento transnacional. Exploro las nociones de autenticidad y respeto en tanto mecanismos a través de los cuales los sikuris

* Extiendo mi reconocimiento a todos los sikuris en Argentina, Bolivia, Chile, Colombia y Perú que compartieron conmigo sus experiencias y comprensiones acerca del movimiento sikuri. Agradezco especialmente a Gina Ayala. También a Marcel Didier, José Salgado, y a los revisores anónimos de la revista por los perspicaces comentarios que hicieron a versiones previas de este artículo. 
negocian su legitimidad para interpretar músicas de origen indigena, y concluyo que sus actividades inspiran estilos de vida alternativos con el potencial de generar transformaciones profundas en la identidad, cultura y sociedad latinoamericanas.

Palabras clave: autenticidad, ciudadanía artística, movimiento sikuri, resurgimiento musical, transferencia cultural.

\title{
"We're Nobody Without the Other": Authenticity and Citizenship in a Transnational Andean Music Revival Community
}

\author{
ABSTRACT
}

Since the 1970s, Latin American cities such as Lima, La Paz, Buenos Aires, Santiago, and Bogotá have witnessed the emergence and development of music scenes focused on the collective interpretation of the Andean Pan flutes known by the aimara name sikus. Despite the fact that most of the participants of these scenes did not grow in family, community or regional contexts in which sikuri musical practices were generationally transferred, today they assume these as their own while adapting their uses and meanings to their own social environments and agendas. Based on several multi-sited fieldwork sessions in the metropolitan Buenos Aires, Santiago, and Bogota scenes, I argue that their growing interconnectedness has given shape to a transnational movement. I also explore the notions of authenticity and respect as mechanisms through which the sikuris negotiate their legitimacy as performers of indigenous Andean music, and conclude that their activities have the potential to transform Latin American identity, culture, and society.

Keywords: artistic citizenship, authenticity, cultural transference, music revival, sikuri movement. 
Durante las últimas décadas, grandes capitales latinoamericanas se han convertido en focos de un movimiento transnacional que aglutina centenares de danzantes e intérpretes de instrumentos y tradiciones musicales andinas de origen indígena, en particular las relacionadas con las flautas de Pan, conocidas con el nombre aimara sikus. Los sikuris (intérpretes de sikus) forman numerosos conjuntos para tocar consortes de estos y otros aerófonos en compañía de diversos tipos de percusión. Estas tradiciones musicales favorecen la participación de individuos con distintos niveles de habilidad musical y, a menudo, son descritas por sus intérpretes como prácticas que promueven valores solidarios. En sincronía con la caracterización de la economía moral andina diseminada por las antropologías andinistas durante las décadas de 1970 y 1980, muchos sikuris celebran estos valores como atributo exclusivo del ethos comunitario que dominaría la vida en las aldeas de los Andes (i.e., dualidad, complementariedad y reciprocidad) ${ }^{1}$.

Pero la mayoría de los sikuris no crecieron en contextos familiares, comunitarios o regionales en los que estas prácticas musicales fueran ejercidas en forma tradicional. Artesanos, obreros, estudiantes, maestros y profesionales de clase media y sectores populares, los sikuris se encuentran a menudo más familiarizados con la cultura hegemónica cosmopolita, que con las tradiciones y formas de vida típicas de los agricultores indígenas en los Andes. Pese a ello, muchos adoptan ciertas prácticas musicales y rituales de las culturas indígenas andinas - en especial aquellas en las que se manifiestan de manera más explícita ideales relacionados con la solidaridad y la equidad - y las adaptan en formas creativas a sus respectivos contextos. Participando en manifestaciones de rechazo a diversas

Reconozco que no es posible elaborar una caracterización incontrovertible de un movimiento cultural tan complejo y que congrega tantos participantes con motivaciones, posturas ideológicas, niveles de compromiso y experiencias tan diversas como este. Las generalizaciones que aquí presento, no obstante, son indispensables para la formulación de teorizaciones que faciliten la comprensión de los procesos de transferencia cultural que los sikuris protagonizan. 
injusticias sociales y articulándose a procesos comunitarios en sus barrios para construir relaciones sociales más satisfactorias, muchos sikuris aseguran que tocar estos instrumentos con respeto constituye un acto de resistencia cultural que contribuye a la creación de una sociedad más justa y fraternal. En breve, conciben la interpretación de la música de los indígenas aimara y quechua como un mecanismo de ciudadanía artística capaz de transformar la sociedad.

Pese a que muchos conjuntos de sikuris establecen como una de sus finalidades replicar estas prácticas musicales y rituales con fidelidad, las operaciones mediante las que transfieren dichos conocimientos desde remotas aldeas andinas hasta el contexto de las ciudades que habitan involucran complejos procesos que a la larga los modifican. Estos procesos no solo implican cambios estéticos, sino que incluyen la transformación de los significados y funciones que los campesinos indígenas originalmente atribuyen a la producción musical. Entre los factores que condicionan la transferencia de dichos conocimientos y prácticas sobresalen la preferencia por determinados paradigmas de autenticidad, la influencia de ciertas predisposiciones culturales, las elecciones prácticas y las inclinaciones involuntarias.

En este artículo exploro una de las adaptaciones más sobresalientes de las que los sikuris son responsables: la caracterización de estos instrumentos y músicas como herramientas de expresión ciudadana y transformación social. Para tal efecto, me enfoco en las escenas sikuri de la ciudad de Buenos Aires, Santiago y el área metropolitana de Bogotá2.

Primero describiré el movimiento sikuri como un movimiento de resurgimiento musical (music revival). Propongo que las escenas que lo componen se encuentran interconectadas a través de un extenso circuito transnacional unificado en torno a la noción de «lo andino», así como a un conjunto de conocimientos y prácticas propias de los indígenas que pueblan la cuenca del Titicaca ${ }^{3}$.

2 La demografía de estas escenas varía significativamente. La escena de Bogotá está conformada por músicos de origen nacional y es, por tanto, relativamente homogénea (Sinti, 2017). Contrasta con la de Buenos Aires, donde diversos flujos migratorios reunieron a participantes de múltiples orígenes étnicos y nacionales que han llevado a los mismos sikuris a diseñar categorías para distinguirse entre sí (Podhajcer, 2015). En Santiago, donde la presencia de residentes peruanos y bolivianos es cada vez más notoria, un intercambio intercultural semejante se encuentra en desarrollo (para una descripción comparativa de estas escenas ver Castelblanco, 2019, pp. 109-113).

3 Entiendo las escenas musicales como instancias de interacción social que gravitan alrededor de diversas prácticas musicales, y donde confluyen participantes que, a partir de sus distintas trayectorias, identidades y estilos de vida, asumen varios roles y grados de implicación mientras 
A continuación, describo la manera en que el indigenismo, las antropologías andinistas y los proyectos culturales asociados a la Nueva canción latinoamericana caracterizaron ciertas prácticas comunitaristas andinas como si fuesen una efectiva respuesta a la ideología capitalista. Describo la importancia simbólica que los sikuris dan a la técnica de interpretación de sus instrumentos, argumentando que los conjuntos de sikuris constituyen espacios idóneos para el cambio de hábitos de pensamiento y práctica con el potencial de generar transformaciones sociales duraderas. Concluyo discutiendo diversos paradigmas de autenticidad con que los sikuris reclaman legitimidad en tanto intérpretes de ciertas prácticas culturales de los indígenas andinos.

Este trabajo se fundamenta en mi propio involucramiento en el movimiento sikuri desde 2007 como miembro de un conjunto en Bogotá, y desde 2013 también como investigador. Debido a la creciente interconexión entre las escenas sikuri de distintas ciudades, en mi investigación no seguí el modelo etnográfico convencional que circunscribe al investigador a un único lugar privilegiado desde el cual realizar observación participante. Al contrario, mi investigación requirió que condujera trabajo de campo multisituado en seis países a lo largo de los últimos siete años. Lo que esto significa en el contexto del movimiento sikuri es que no solo hice entrevistas semiestructuradas y recogí testimonios, sino que también toqué música y bailé, aculliqué hojas de coca, bebí y pasé largas horas escuchando música y discutiéndola con mis interlocutores.

Más importante aún, asistí a los ensayos de numerosas agrupaciones con diversas afiliaciones étnicas, regionales y nacionales, así como con variados niveles de experiencia y comprensión sobre las prácticas musicales andinas; participé en ceremonias y procesiones religiosas en las que la música jugó un papel central, como en encuentros, festivales y congresos de sikuris. Marché por emblemáticas avenidas exigiendo una variedad de demandas sociales junto a ensambles ad hoc, y asistí a más talleres de «cosmovisión andina» de los que hubiera deseado. Más importante aún, experimenté aquellos mismos sentimientos de identificación colectiva que muchos celebran como uno de los más potentes atributos de esta forma de hacer música, y fui testigo de los valores solidarios que esta práctica musical inspira.

Aun cuando antes de asumir mi papel como etnógrafo del movimiento, ya estaba involucrado con grupos de personas con quienes compartía el gusto por

comparten gustos musicales y se distinguen de otros (ver Peterson y Bennett, 2004; Mendívil y Spencer, 2016; Pedro y otros, 2018, etcétera). 
esas mismas actividades —es decir, ya era un «participante»-, al convertirme también en «observador» mi pertenencia al «adentro cultural» empezó a ser menos transparente. Para mi fortuna, un influyente sector del movimiento sikuri ejerce una vocación reflexiva semejante a la que caracteriza a los etnógrafos. Como explicaré más adelante con mayor profundidad, esta falange intelectual autogestiona congresos y publicaciones de diverso tipo que, en suma, constituyen un foro para el intercambio de experiencias, reflexiones y teorizaciones relacionadas con algunos de los mayores dilemas que la interpretación de estas músicas de origen indígena conlleva. En breve, ni la reflexión ni la escritura son ajenas al movimiento sino, por el contrario, ejercicios que gozan de un lugar destacado dentro del mismo. Mi trabajo se enmarca dentro de este foro y busca entrar en diálogo con otros trabajos que contribuyen a historizar y enriquecer la actividad de los sikuris.

\section{UN MOVIMIENTO DE RESURGIMIENTO MUSICAL}

Algunas de las actitudes más generalizadas entre los participantes del movimiento sikuri sugieren que es pertinente caracterizarlo como un movimiento de «resurgimiento musical» ${ }^{4}$. De acuerdo con Livingston (2014), existen ciertas actitudes que son comunes a los participantes de este tipo de movimientos. Entre ellas sobresalen dos que son centrales entre los sikuris: su tendencia a asumir la misión de restaurar o preservar tradiciones que imaginan en peligro de desaparecer, y su apropiación de estas en virtud del legado histórico y los valores asociados que conllevan o que les atribuyen. Por efecto de ambas actitudes, los resurgentistas musicales suelen percibir su actividad como una labor altruista que ofrece una

\footnotetext{
Las traducciones de la voz inglesa music revival al castellano son, en general, insatisfactorias. Muchas retienen el prefijo re-, que denota una relación con el pasado (e.g., recuperación, renacimiento, revitalización). Sin desestimar otras traducciones, me inclino aquí por la locución «resurgimiento musical» y por llamar «regurgentistas» a sus agentes. Concuerdo con Hill y Bithell (2014) en cuanto a que este concepto expresa el esfuerzo deliberado de los resurgentistas de establecer una continuidad entre el pasado y el presente a través de ciertas prácticas musicales. Esta noción resalta su voluntad de mantener vivas dichas formas culturales, y no necesariamente resucitarlas. Dicho de otro modo, sugiere que más que exhumar expresiones culturales extintas, los resurgentistas las hacen visibles ante una sociedad dominante que las ha ocultado o que les ha sido históricamente indiferente (p. 5).
} 
alternativa a la alienación, inequidad y degradación moral promovida por la cultura dominante (p. 61) .

Al respecto, resulta muy elocuente la manera en que el guía de un importante conjunto bogotano solía declarar la misión de la agrupación durante sus presentaciones públicas: «Nosotros investigamos, rescatamos y difundimos la música ancestral de nuestros pueblos originarios para enfrentar cinco siglos de opresión colonialista [...] [y] la enfermedad del capitalismo» (Simón, diciembre de 2018).

Como documentó el influyente etnomusicólogo Thomas Turino (1993), esta forma de concebir la interpretación de sikus marcó los albores del movimiento en Lima durante la década 1970. Para los músicos de la Asociación Juvenil Puno (AJP) - agrupación conformada por estudiantes puneños de clase media que se establecieron en Lima- «el acto mismo de tocar el siku constituía una demostración de solidaridad con la población indígena oprimida, un rechazo al imperialismo cultural extranjero y un ícono del colectivismo» (mi traducción) (p. 146). En breve, los músicos de la AJP transformaron los usos agropecuarios, devocionales y festivos que sus paisanos suelen otorgar a la interpretación de sikus, en herramientas de expresión ciudadana.

Entre los sikuris en Buenos Aires, Santiago y Bogotá hoy circulan discursos que, de forma semejante, combinan romanticismo y sentimientos indigenistas con activismo cultural y político. En estas ciudades numerosos conjuntos de sikuris declaran su principal objetivo salvaguardar y difundir dichas tradiciones musicales para defenderlas de la globalización y salvarlas de la extinción. Entre sus miembros, muchos además imaginan las prácticas musicales andinas y los valores solidarios que les atribuyen como una estrategia eficaz para cuestionar la narrativa histórica oficial y promover una sociedad más íntegra, justa y fraternal que sobrepase los límites nacionales (Barragán y Mardones, 2015, pp. 6, 11-13; Ibarra, 2012, p. 9; Podhajcer, 2011, p. 275; Vega, 2016, pp. 1067, 1073, 1076) ${ }^{7}$.

5 Cuando digo que muchos sikuris imaginan que ciertas tradiciones musicales se hallan en peligro de extinción, no quiero decir que la globalización y la cultura de masas no representen una amenaza para su continuidad. De hecho, la presencia de muchas de estas expresiones en fiestas patronales y otros contextos ha disminuido en años recientes debido a múltiples factores, incluyendo la preferencia por las bandas de bronce. Mi intención es resaltar el estado de fragilidad en que muchos sikuris perciben que se encuentran algunos de los estilos musicales que interpretan y que - precisamente porque son objeto de revaloración, concursos y declaratorias patrimoniales - están lejos de desaparecer.

6 En este artículo he resuelto emplear seudónimos para proteger la privacidad de quienes compartieron conmigo sus testimonios.

7 Resulta difícil establecer el grado de influencia que la AJP tuvo en la configuración discursiva de las escenas sikuri fuera de Perú. Como explica Ríos (2008), la politización de géneros e 
Esta manera de entender la música andina coincide con los atributos más sobresalientes que la noción de «lo andino» ha acarreado desde su surgimiento a fines del siglo XIX en tanto expresión de descontento con la modernidad, la historia oficial, la idea de nación, y en suma, como propuesta de transformación social $^{8}$.

\section{UN EJERCICIO DE CIUDADANÍA}

Los sikuris suelen expresar su afinidad con valores solidarios que describen como opuestos a la formación cultural capitalista: el neoliberalismo y el colonialismo eurocéntrico, cristiano y patriarcal. Esta postura ideológica es consecuente con las caracterizaciones de «lo andino» que produjeron las literaturas indigenistas y, en especial, las antropologías andinistas de las décadas de 1970 y 1980.

Como indica Poole (1992), los antropólogos de esta generación interpretaron «lo andino» «como algo opuesto al dominio de las prácticas sociales «modernas» constituidas por las relaciones capitalistas de producción e intercambio, la economía de mercado y la lucha de clases» (p. 216). En sincronía con esta caracterización de la vida en los Andes, muchos participantes del movimiento sikuri imaginan las prácticas musicales andinas como vehículo idóneo para la promoción de valores solidarios y, más aún, como respuesta al individualismo y la degradación moral que promueve la economía capitalista (Barragán y Mardones, 2015, pp. 35-36; Ibarra, 2012, p. 9; Sánchez, 2013, pp. 371-374)9.

instrumentos andinos obedece a un proceso histórico que se remonta a la llegada de la folklorista Violeta Parra a París en 1955 (pp. 153-157). Pese a que en los inicios del movimiento muchos sikuris en Lima rechazaron la música andina folklórica-popular de agrupaciones como Quilapayún (Sánchez, 2013, p. 372), expresaron una asociación análoga entre músicas e instrumentos andinos y diversas inclinaciones políticas de izquierda. Sea como fuere, es claro que el contexto político del período que dio origen a cada escena sikuri impactó sus respectivos metarrelatos (la Guerra fría, la emergencia de guerrillas, las dictaduras en el Cono sur, la industria discográfica que popularizó la Nueva canción, las políticas del multiculturalismo, etcétera).

8 Ríos (2008) sugiere que la asociación temprana entre «lo andino» y posturas políticas de izquierda puede atribuirse a la acogida que gozó el libro de Louis Baudin, L'Empire Socialiste des Inka (París, 1928), entre círculos intelectuales europeos durante la primera mitad del siglo XX (p. 154).

9 «Lo andino» es un discurso esencial acerca del «Otro» producido por agentes externos, e impuesto sobre los habitantes de los Andes para señalar una frontera de orden étnico y cultural. Es un constructo que asume que todos los habitantes de esta región montañosa poseen idénticas inclinaciones culturales, a la vez únicas y coherentes, que incluirían percepciones, entendimientos, valores, símbolos y prácticas. La noción de «lo andino» fue construida por 
Puesto que para producir una melodía con sikus es indispensable la colaboración coordinada entre parejas de músicos, muchos sostienen que la técnica en que se fundamenta su interpretación es una alegoría de los valores solidarios de la economía moral andina. Mientras que uno de los músicos sopla el siku de seis tubos — conocido con el nombre aimara ira («el que guía»o «el que pregunta») - , el otro sopla el siku de siete tubos — llamado arka («el que sigue» o «el que responde»). En virtud de la identidad opuesta y a la vez complementaria de ambos tipos de sikus, solo es posible producir la escala musical completa y, por extensión, una melodía, mediante la colaboración coordinada entre parejas de músicos que intercambian los sonidos de sus respectivos instrumentos, tal y como en un diálogo.

\section{Figura 1. Sikuris intercalando las notas de sus instrumentos durante un festival en Buenos Aires}

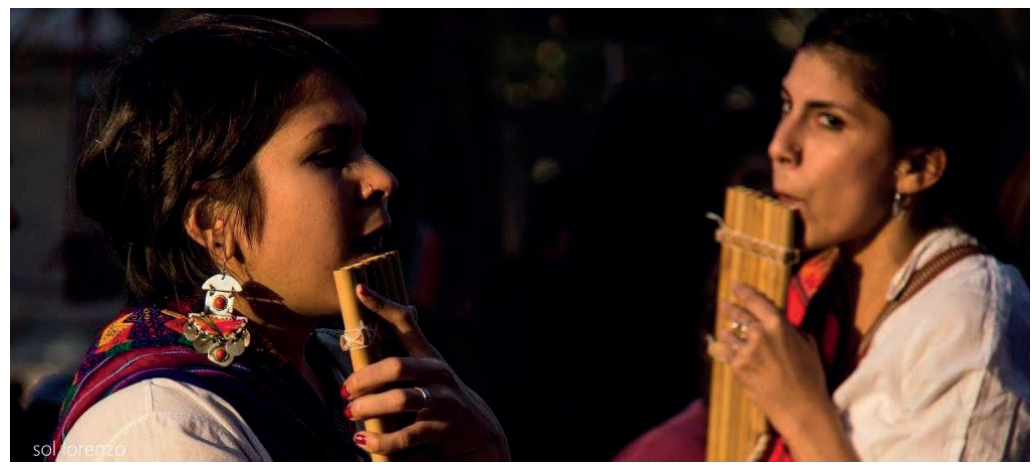

Fotografía: Sol Lorenzo, agosto de 2016.

folkloristas, escritores, antropólogos y políticos en la convergencia de sus respectivas agendas investigativas y preocupaciones políticas. Su aparición oficial se produjo a través del volumen 2 del Handbook of South American Indians (1946), una obra enmarcada dentro de la corriente de los estudios de «área cultural» cuyo propósito consistía en conceptualizar la relación entre territorio y cultura como entidades totales (De la Cadena, 1990, p. 67; Poole, 1992, p. 212). El propósito comparativo que caracterizó el empleo inicial del concepto se diluyó con el paso de los años. Al mismo tiempo, un sector de la academia con antecedentes indigenistas promovió la ideologización de la noción de «lo andino» y definió algunos de sus atributos, como la dualidad y la reciprocidad, como si fuesen rasgos culturales específicamente andinos (De la Cadena, 1990, pp. 67-68). Más aún, definió «lo andino» por oposición a la formación cultural cosmopolita hegemónica (i.e., capitalista, cristiana y modernista) (Poole, 1992, p. 216). Como consecuencia, distintos sectores sociales percibieron «lo andino» como algo que debía ser destruido, superado, asimilado, valorado, celebrado, transformado o rescatado dependiendo sus respectivos programas políticos y económicos (Van Dam y Salman, 2003). 
Muchos sikuris celebran esta técnica de interpretación musical como epítome del ethos comunitario andino, e incluso como reflejo de las «estructuras del pensamiento andino» (dualidad, complementariedad y reciprocidad) (ver Baumann, 1996). Acaso una anécdota contribuya a iluminar los significados sociales que los sikuris atribuyen a esta técnica: hace un tiempo, al concluir uno de los festivales de sikuris más prominentes en la ciudad de Buenos Aires, un grupo de sikuris colombianos residentes en la capital argentina se reunió en casa de un amigo para conversar, tomar algo y bailar. Alrededor de una jarra de fernet con coca (un cóctel popular en Argentina), la conversación viró hacia las formas en que nuestras vidas habían cambiado desde que nos hicimos sikuris. Al fin y al cabo, todas las personas presentes en la sala habíamos sido iniciadas en este tipo de música en Bogotá y, poco después, habíamos partido al extranjero. Luego de algunos intercambios nostálgicos sobre el tema, mi amiga Violeta declaró con ojos centellantes: «no somos nadie sin el otro».

Todos en la sala comprendimos que aludía a la técnica de interpretación sikuri para la cual es indispensable la colaboración coordinada entre pares. Pero mi amiga fue más allá con su máxima: destacó la importancia de los valores colaborativos que los conjuntos de sikuris suelen promover. Celebró la igualdad, la solidaridad y el colectivismo como medio para generar bienestar común, rechazando el individualismo y la competencia. Más aún, desestimó la noción de identidad como atributo individual pues, en ausencia del otro, «no somos nadie». Para mi amiga, como para muchas personas que conozco, integrar un conjunto de sikuris es una experiencia transformadora que fomenta cambios positivos tanto en los individuos como en la sociedad.

Turino (2016) propone que la producción musical participativa - como la que caracteriza los conjuntos de sikuris-, es un recurso con el potencial de generar formas duraderas de ciudadanía alternativa. A diferencia de los movimientos políticos que emplean música y danza de forma estratégica para provocar transformaciones sociales dramáticas, las acciones más bien sutiles pero continuas de quienes participan en estas cohortes sociales tienen efectos profundos sobre la sociedad en el tiempo. Dichos efectos ocurren como consecuencia del cambio de los hábitos fundamentales de pensamiento y práctica que experimentan sus participantes.

Los principios en que se fundan las cohortes sociales dedicadas a estas prácticas musicales son decisivos en este proceso. Efectivamente, estas a menudo operan de acuerdo con valores y prácticas opuestas al ethos capitalista, están abiertas a cualquier persona interesada y se organizan en torno a la construcción 
de consenso igualitario. Además, se fundamentan en actividades placenteras como tocar música, que facilitan a sus participantes involucrarse de forma prolongada y repetir a través del tiempo un repertorio de prácticas que a la larga terminan por transformar sus hábitos.

Siguiendo a Turino, argumento que los conjuntos de sikuris constituyen espacios privilegiados para el cambio de hábitos de pensamiento y práctica y, por extensión, para el desarrollo de formas alternativas de socialización con el potencial de transformar la sociedad. La participación de una persona en un conjunto de sikuris estimula y desarrolla sus habilidades artísticas, le facilita establecer interacciones sociales significativas sin la carga que para algunas personas implica la comunicación verbal, le proporciona diversión, alegría, acceso a redes de amistad y apoyo mutuo, y el sentimiento de pertenencia a una comunidad. También fomenta valores solidarios y la apreciación de culturas distintas a la dominante, favoreciendo las relaciones interculturales. A nivel comunitario, los conjuntos de sikuris constituyen instancias idóneas para generar capacidad cultural colectiva y de acción social organizada. En pocas palabras, empodera a los individuos y las comunidades, mejorando su calidad de vida.

Pero Turino es claro en advertir que las transformaciones sociales que las cohortes de música participativa pueden promover ocurren a pequeña escala debido a que no son necesariamente conscientes, premeditadas o estratégicas, y a que se encuentran — por definición—, fuera de los circuitos capitalistas del mercado y la publicidad. Esto es precisamente lo que ocurre con los sikuris.

Kim Dunphy (2018) propone tres categorías para analizar las maneras en que los grupos artísticos pueden generar cambios sociales: el paradigma terapéutico (en el que el cambio es producido a nivel de los individuos mediante el proceso curativo de las artes utilizadas de modo terapéutico), el desarrollo cultural comunitario (en el cual el cambio ocurre en la esfera comunitaria como resultado de la interacción social creativa entre los participantes) y la acción cívica/social (cuya estrategia consiste en influenciar la opinión pública y la toma de decisiones a través de actividades artísticas).

Aunque el impacto inicial de los conjuntos de sikuris ocurre en el ámbito individual y comunitario, potencialmente puede extenderse a las otras dimensiones sociales descritas por Dunphy. Por ejemplo, un miembro de un conjunto en Santiago puede desarrollar sus habilidades individuales como músico, construir comunidad a través de su participación en la escena local, e influir en la opinión de los espectadores casuales de un pasacalle en el centro de la ciudad acerca del valor social y cultural de los inmigrantes bolivianos. Todos los resultados (indivi- 
duales, comunitarios y cívicos) son posibles. Pero mientras que las dos primeras formas de transformación social ocurren a nivel individual y en la intimidad de los ensayos grupales, la acción cívica/social solo es posible en espacios públicos.

\section{SIKURIS A LA PLAZA}

Aunque muchos sikuris expresan su voluntad de replicar con la mayor precisión posible la música de los indígenas andinos, los procesos mediante los que transfieren dichas prácticas y conocimientos están condicionados por predisposiciones estéticas, elecciones prácticas e inclinaciones involuntarias. Como resultado, sus interpretaciones suelen comportar características sonoras que hacen de ellas productos culturales novedosos (Castelblanco, 2018). Pero las transformaciones a las que los sikuris someten estas prácticas musicales trascienden el ámbito estético, pues tienen importantes efectos sobre los usos y significados que sus intérpretes originales atribuyen a la producción musical, con lo cual se tornan funcionales a sus propios contextos y agendas.

Acaso una de las elecciones más frecuentes consiste en ignorar o desafiar la prescripción social que en muchas comunidades agrícolas de los Andes disuade a las mujeres de interpretar instrumentos de viento (Vega, 2016). Muchos conjuntos también privilegian la interpretación de sikus sobre otros aerófonos andinos y los tocan a lo largo de todo el año sin atender a los calendarios agropecuarios e instrumentales que en las comunidades campesinas suelen limitar su uso a temporadas específicas del año (Castelblanco, 2019). Pero sin lugar a duda una de las transformaciones más importantes tiene que ver con el uso que muchos sikuris dan a la música como herramienta de expresión ciudadana en marchas y protestas politizadas - una función insólita entre los agricultores andinos.

Ya sea marchando como conjuntos de sikuris formalmente establecidos o en grandes comparsas integradas de manera ad hoc por miembros de distintas agrupaciones, muchos sikuris ocupan las principales avenidas y plazas de sus respectivas ciudades en diversas ocasiones. Estas incluyen manifestaciones políticas y culturales que hacen parte del calendario cívico anual de cada ciudad, así como protestas que surgen en respuesta a eventos políticos coyunturales.

Entre las ocasiones que convocan a los sikuris cada año en Buenos Aires, Santiago y Bogotá, sobresalen las manifestaciones conmemorativas de la invasión de América cada octubre. Tanto en Buenos Aires como en Santiago, sikuris de distintas agrupaciones suelen marchar para manifestar su rechazo a las dictaduras militares que se impusieron en ambos países en la década de 1970. Otras fechas 
importantes incluyen los pasacalles por el Día de la Chakana, Inti Raymi y el Día de Todos los santos o Wiñay Pacha, así como los carnavales de barrios populares (ver Barragán y Mardones, 2015; Ibarra, 2012; Taypi Aru (ed.), 2011).

Figura 2. Sikuris en Santiago marchan conmemorando el inicio de la dictadura de Augusto Pinochet

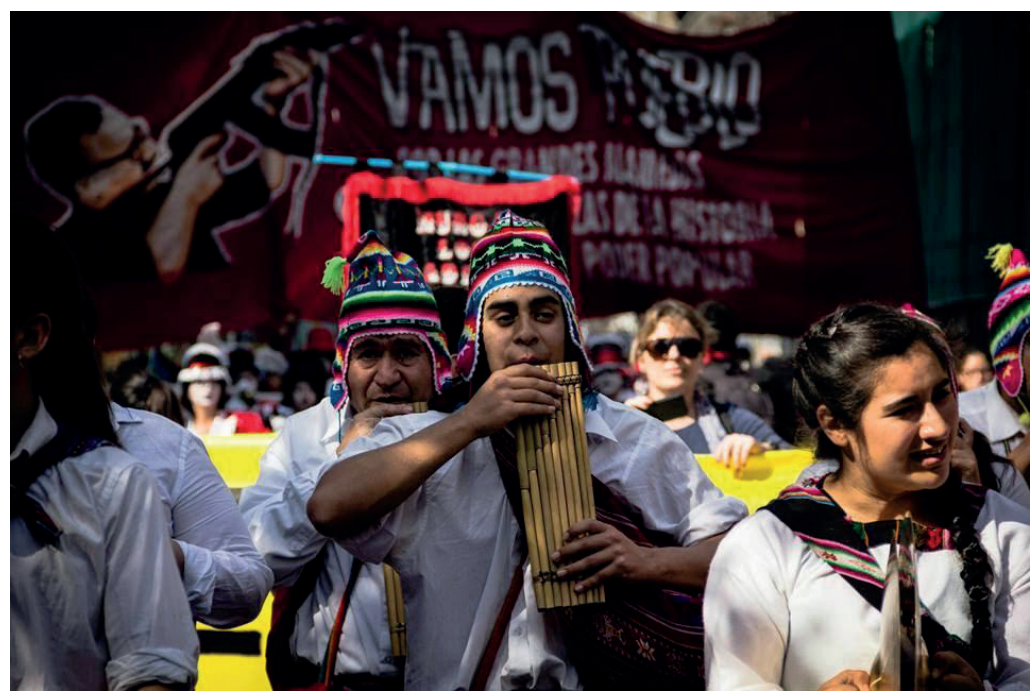

Fotografía: Miguel Hidalgo, septiembre de 2013.

La participación de los sikuris en manifestaciones que responden a coyunturas políticas específicas es recurrente, por lo que aquí solo me limitaré a enumerar algunas de ellas. En octubre de 2008 en Bogotá, por ejemplo, los sikuris recibieron a los cerca de 60000 indígenas del suroccidente colombiano, principalmente nasa, en la jornada final de la marcha que emprendieron desde el departamento del Cauca hasta la capital para reclamar al gobierno por los asesinatos, secuestros y desplazamientos forzosos de que son víctima a manos de diversos actores armados, incluyendo fuerzas estatales. En Buenos Aires, al menos un centenar de sikuris acompañó en distintas ocasiones a los cerca de cuarenta miembros de la comunidad indígena qom que desde 2010 abandonaron la provincia de Formosa para instalarse en un campamento en pleno centro de la ciudad en reclamo por el despojo de sus tierras (Barragán y Mardones, 2015, p. 34). En Santiago durante 2011, numerosas comparsas ad hoc de sikuris y lakitas participaron en las marchas del movimiento estudiantil y docente que se hicieron habituales a lo largo 
del año, y a través de las que atrajeron la atención nacional sobre la necesidad de reformar el sistema educativo escolar y universitario ${ }^{10}$.

Durante estas marchas, especialmente en Buenos Aires y Bogotá, es habitual que los miembros de distintos conjuntos se unan en grandes comparsas ad hoc para interpretar temas de un repertorio ampliamente difundido que incluye melodías como «Ausencias», «Corazón mío», «Flor de cactus» y «Wiphalas». Los sikuris muchas veces adaptan los cánticos de temática bucólica y amor romántico que suelen acompañar las versiones folklorizadas de estas melodías, para verbalizar sus denuncias de acuerdo con cada ocasión.

La versión más popular de «Corazón mío», por ejemplo, canta: «Corazón mío no llores / no llores ni tengas pena. / Llorarás cuando yo me vaya / sufrirás cuando yo me ausente. / Corazón mío / llorarás cuando yo me ausente». En contraste, una de las adaptaciones más recurrentes que cantan los sikuris durante marchas cívicas dice: «Pueblo mío ya no llores / no llores ni tengas pena. / Las injusticias de este mundo / se acabarán para siempre. / Ay, pueblo mío / se acabarán para siempre».

Las sikuris que en Buenos Aires participaron recientemente en las manifestaciones del movimiento «Vivas y libres nos queremos», enfocado en visibilizar y condenar la violencia contra las mujeres, adaptaron la versión más difundida de «Tesorito» y en su lugar cantaron: «Una cultura patriarcal / nunca va a triunfar / por más que nos quieran oprimir / siempre vamos a luchar. / Mujeres, seguimos de pie / vivas y libres nos queremos / siempre vamos a luchar» ${ }^{11}$.

En su paso por Bogotá, un influyente músico chileno participó en la fundación de un conjunto importante en la escena local. El repertorio de este grupo incluye una melodía instrumental, original de la isla de Taquile (Puno, Perú), para la que el chileno ideó una letra que suelen cantar en sus intervenciones públicas y que dice: «Si vienen transnacionales / trayendo muerte a nuestros ríos / contaminando el humedal / dañando la tierra a raudal. / Y creen que a nadie importa / su vil manera de usurpar / los paraísos perdidos / por la escoria institucional. / Levántense sikuris y a luchar / la tierra no se vende al capital». En síntesis, las

10 Se conoce como lakitas a una extensa familia de consortes de flautas de Pan cuyas características varían sustancialmente a través de las regiones de los Andes centrales donde son interpretadas en Bolivia (La Paz y Cochabamba), Perú (Puno) y Chile (Tarapacá, Arica y Parinacota) (Baumann, 1982; Mora (ed.), 2012; etcétera). En Santiago las comparsas de lakitas superan numéricamente a los conjuntos de sikuris.

11 En el contexto de este movimiento, las adaptaciones creativas de las sikuris expusieron la misoginia intrínseca a los cantos que acompañan las versiones folklorizadas de dichas melodías, y en las cuales la voz lírica (masculina por excelencia) se retrata como víctima de una mujer traicionera, ingrata o pérfida. 
letras que los sikuris inventan o adaptan para acompañar diversas melodías evocan imágenes de resistencia cultural y abordan problemáticas como la injusticia social, la inequidad de género y la destrucción de la naturaleza.

Por otro lado, en ciudades donde reside gran número de personas de origen boliviano y peruano, como Buenos Aires y Santiago, ciertos conjuntos de sikuris se articulan a las fiestas y celebraciones del ciclo vital que organizan estas colectividades, como ceremonias de corte de pelo y matrimonios. Algunos también se suman a las misas y pasacalles que regularmente ofrecen en honor a los santos patronos y vírgenes de sus regiones y países. La participación de los conjuntos de sikuris en estas instancias suele ser motivo de discusión entre sus miembros, pues mientras unos rechazan participar en celebraciones católicas argumentando que constituyen desviaciones coloniales de las auténticas fiestas prehispánicas, otros consideran que hacerlo es una experiencia que les aproxima a los contextos actuales - y por tanto auténticos- de producción musical (Gavazzo, 2017; Vega, 2016). Para estos últimos, participar en fiestas religiosas es una forma de expresión ciudadana en tanto les permite manifestar su rechazo a la xenofobia y el racismo de un sector de la sociedad nacional, y contribuye a la visibilización y valoración de los residentes extranjeros.

Así lo manifestó Raquel poco antes de unirse en procesión al conjunto de sikuris que escoltaría la estatua de la Virgen de Copacabana alrededor de la Plaza de Armas de Santiago: «Para nosotros es importante acompañar a los hermanos bolivianos porque aquí en Santiago ellos tienen que soportar mucha exclusión, mucho rechazo. Estar con ellos es una forma de decir: «Ustedes son bienvenidos aquí porque somos latinoamericanos, porque somos hermanos»»» (agosto de 2016).

Aunque las motivaciones que tienen los sikuris para participar en manifestaciones como las señaladas a veces son tácitas, con frecuencia responden a agendas claras relacionadas con las circunstancias sociales, culturales y políticas que les rodean. En breve, sus motivaciones trascienden la búsqueda de placer estético y con frecuencia devienen ejercicios cívicos. Así, además de hacerlo por el gusto que proporciona tocar música en grupo, los sikuris lo hacen para preservar tradiciones musicales, expresar su rechazo al colonialismo interno y el imperialismo cultural extranjero, demostrar su solidaridad con la población indígena oprimida o promover transformaciones culturales en favor de una sociedad equitativa y fraterna. Debido al carácter misional de las motivaciones que convocan a los sikuris, considero oportuno describir sus actividades como parte integral de un movimiento.

Esta conceptualización refleja características fundamentales de las actividades de los sikuris. Primero, porque resalta el hecho de que las acciones de sus 
participantes son una forma de activismo - en el sentido amplio del término. En efecto, el movimiento comprende individuos con distintos niveles de compromiso que van desde aquellos que hacen esfuerzos intencionales para generar cambios culturales y sociales, hasta aquellos por cuya dedicación a diversas causas políticas podrían ser descritos como «militantes». También porque —al hablar de un movimiento sikuri- es posible dar cuenta del flujo dinámico de personas, conocimientos y prácticas que hoy da forma a un complejo circuito transnacional.

\section{EL ARCHIPIÉLAGO TRANSNACIONAL SIKURI}

En trabajos previos he caracterizado este circuito como un «archipiélago cultural» invocando la metáfora geográfica formulada por el etnohistoriador John Murra (Castelblanco, 2014). Con base en el análisis de documentos coloniales, Murra (1972) desarrolló un modelo económico para comprender las relaciones comerciales entre grupos étnicos emparentados en los Andes. En pocas palabras, el modelo postula que sociedades andinas prehispánicas establecieron colonias en zonas ecológicas distantes - a menudo discontinuas y en ambas laderas de los Andes - con el fin de acceder a los bienes producidos en ellas. Resumiendo, establecieron relaciones recíprocas de intercambio dentro de su propia comunidad con el fin de diversificar sus recursos sin necesidad de involucrarse en relaciones comerciales con otros grupos étnicos, manteniendo así su autosuficiencia.

Sugiero que el circuito transnacional a través del que fluyen personas, instrumentos musicales, repertorios, símbolos e ideologías asociadas a la música sikuri, puede ser conceptualizado como un archipiélago cultural, conformado por «islas culturales» de distintos tamaños y niveles de influencia sobre las demás. Esta caracterización enfatiza el flujo multidireccional que conecta grupos discontinuos, y a menudo geográficamente distantes, en que las prácticas asociadas al sikuri son (re)producidas. Estas «islas culturales» pueden también ser concebidas como escenas musicales, es decir, como agrupaciones informales de individuos que comparten un gusto musical y expresan su identidad colectiva para distinguirse de los demás, especialmente de la cultura dominante, a través de cierto tipo de música, vestimenta, y conducta (ver nota 5).

El origen de cada escena sikuri, así como algunos de sus mayores hitos, están atravesados por fertilizaciones cruzadas semejantes a las que dan forma a los archipiélagos culturales descritos en el modelo de Murra: en 2010, por ejemplo, el músico y educador argentino Mauricio Cucien viajó a Bogotá, donde enseñó 
a los sikuris de la Comunidad zampoñas urbanas el emblemático tema «Cinco siglos» — adaptación de un motivo melódico original de la Provincia Camacho (La Paz, Bolivia) a cargo de pioneros de la escena sikuri de Buenos Aires. Más tarde esta pieza fue diseminada entre las demás agrupaciones de la escena bogotana con tal éxito, que hoy constituye parte fundamental de su repertorio. Un proceso análogo ocurrió en otras escenas a nivel internacional. Es por esto que muchos consideran «Cinco siglos» como el himno de los sikuris — un poderoso símbolo de identidad común que contribuye a cohesionar el movimiento.

Ahora bien, dentro de estas escenas o «islas culturales», la cuenca del Titicaca juega un papel central, pues constituye el epicentro de la autenticidad (musical, ritual, espiritual, etcétera) a la cual todos aspiran. Allí se encuentra el remoto pasado arqueológico e histórico que legitima las prácticas que son objeto de resurgimiento musical. De allí provienen los instrumentos elaborados por artesanos locales con materiales originales de acuerdo con preceptos vernáculos. También una variedad de estilos musicales y repertorios regionales. Y lo que es más, a esa región están asociados aquellos músicos a quienes muchos reconocen como maestros legítimos de quienes aprender dichas músicas.

Figura 3. Focos de producción de algunos de los estilos musicales que la cohorte de sikuris «resurgentistas» interpreta

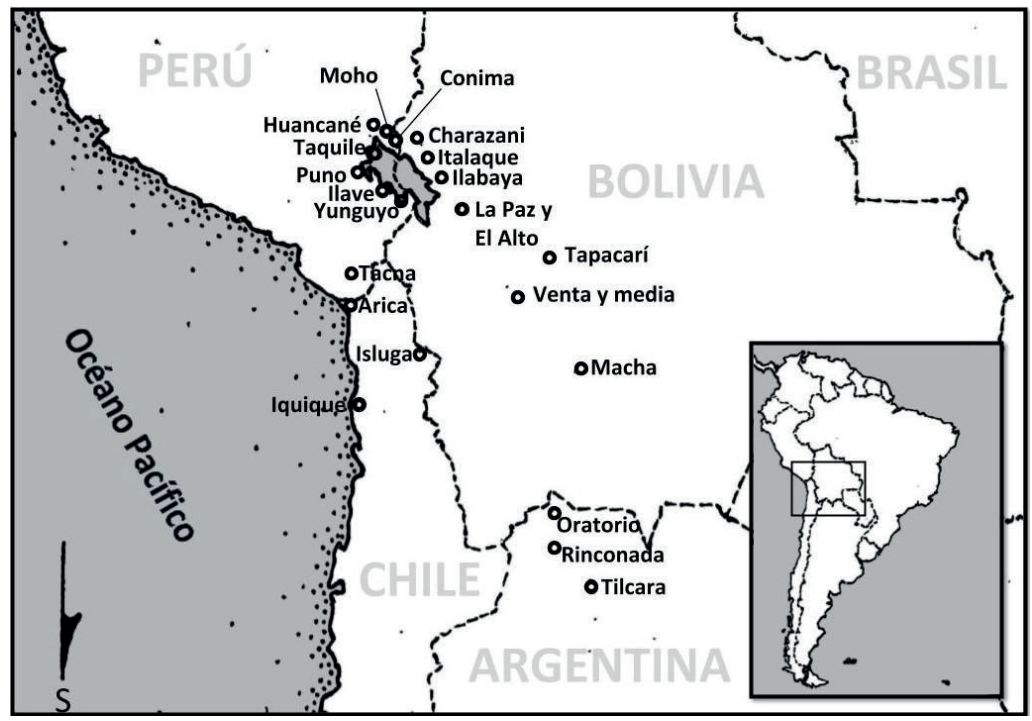


Siguiendo este postulado, la identidad cultural de las islas que conforman el archipiélago sikuri divide a sus participantes en dos grandes cohortes: los músicos «hechos en casa» (i.e., personas que crecieron interpretando este tipo de música como parte de sus prácticas familiares, comunitarias o regionales durante generaciones) y los músicos «resurgentistas» (i.e., nuevos entusiastas típicamente cosmopolitas que crecieron en suburbios o ciudades donde no había una tradición musical análoga establecida) ${ }^{12}$.

Dentro de la geografía simbólica de este archipiélago, la ciudad de Puno y Lima predominan como las islas más grandes. Buenos Aires, pese a la enorme distancia que le separa de las cumbres andinas, es una escena muy influyente. Santiago tiene una escena intensa con calendarios de festividades bien establecidos, mientras que Bogotá cuenta con una escena creativa en proceso de expansión.

Los procesos inmigratorios de cada ciudad y la presencia o ausencia de músicos «hechos en casa» constituyen factores decisivos en la conformación y configuración de las escenas sikuri (ver Castelblanco, 2018; Gavazzo, 2017; Sánchez, 2013; Sinti, 2017; Podhajcer, 2011; Vega, 2016). Aunque cada escena o «isla» sikuri tiene un número distinto de miembros y un grado variable de influencia sobre las demás, sus participantes a menudo comparten un sentido de afinidad entre ellos que trasciende identificaciones de tipo nacional. Este sentido de afinidad se debe al hecho de que los sikuris suelen dar mayor importancia a sus semejanzas que a sus diferencias. En buena medida, este sentimiento de identificación colectiva también puede atribuirse al impacto de la llamada «música andina latinoamericana», que goza de gran popularidad entre los participantes del movimiento sikuri, y que en muchos casos precede sus gustos musicales.

12 Estas categorías analíticas fueron originalmente formuladas por Turino (2018) para describir las escenas norteamericanas de música y danza old-time, que orbitan en torno a ensambles participativos de cordófonos acústicos guiados a menudo por violines en compañía de guitarras, banjos y mandolinas. Para efectos del presente estudio, considero pertinente conceptualizar la participación de los individuos que conforman las escenas sikuri mediante categorías análogas, debido a que hacen énfasis en los paradigmas estéticos y las comprensiones acerca de la música que dan forma a su actividad musical, y no en aspectos extramusicales contingentes o subsidiarios, como sus filiaciones étnicas, regionales o nacionales. Turino advierte que distinguir entre ambas cohortes de músicos resulta cada vez más difícil debido a que muchos músicos «hechos en casa» (homegrown) asumen actitudes «resurgentistas» (revivalist), mientras que las nuevas generaciones de músicos que crecen en ambientes «resurgentistas» pueden ser también considerados como «hechos en casa». Este tipo de diferenciación, no obstante, sigue siendo relevante para algunas personas en lo relativo a la autenticidad (Turino, 2018). Para una discusión más detallada sobre la aplicación de ambas categorías al contexto del movimiento sikuri en Perú, ver Castelblanco (2018). 
A partir de la década de 1960, los artistas de la Nueva canción chilena y otros proyectos culturales asociados promovieron la música andina folclórica como modelo para alcanzar la integración latinoamericana (e.g., Los Calchakis, Los Incas, Inti-Illimani, etc.). Estos músicos comprometidos reunieron instrumentos y ritmos musicales de diversas tradiciones latinoamericanas, haciendo énfasis en la zona andina (ver Céspedes, 1984; Ríos, 2008). Para ellos, este estilo musical multifacético evocaba la unidad que Sudamérica habría experimentado hacia el final del período precolombino, cuando los límites del Imperio Inca se expandieron más allá de las fronteras actuales de Ecuador, Perú y Bolivia, hasta el norte de Chile, el noroeste argentino y el suroccidente colombiano (Ríos, 2008, p. 156). Desde su punto de vista, la música andina folclórica tenía el potencial necesario para renovar la unidad latinoamericana.

Muchos sikuris explican hoy su sentido de identificación colectiva siguiendo un planteamiento semejante al formulado por los artistas de la Nueva canción y su agenda de integración, es decir, restando importancia a sus respectivas identidades nacionales en favor de la unidad de la Patria grande. Para la mayoría de sikuris con quienes he conversado sobre este tema, sin embargo, su sentimiento de identidad común reside en la experiencia compartida de interpretar tradiciones e instrumentos musicales que reflejan en modo explícito el ethos comunitario andino. En palabras de Rafael, uno de los músicos que participa en la escena de Santiago, «las fronteras son una pura ilusión [...] hermano [...] cuando uno toca el siku toda esa [ilusión] se deshace porque uno se da cuenta que son más [los aspectos] que nos unen que [aquellos] que nos separan. Una relación entre hermanos, entre familia... así es ser sikuri» (junio de 2015).

Ahora bien, este sentimiento de comunión suele intensificarse debido a una actividad que se encuentra íntimamente ligada a la interpretación de sikus: la danza. Los músicos indígenas suelen tocar bailando y el éxito de su intervención a menudo es medido por su capacidad de motivar a los presentes a bailar en torno suyo. Tan importante es la danza, que cuando los campesinos indígenas se refieren a la interpretación musical suelen emplear verbos en aimara y quechua que aluden a bailar y no a tocar (Baumann, 1996, pp. 18-19; Turino, 1993, pp. 58-59).

Las danzas de los sikuris incluyen formaciones estáticas, desplazamientos, figuras coreográficas y pasos cuyas variaciones revelan filiaciones regionales. Existe, sin embargo, una coreografía ampliamente difundida basada en una estructura circular que puede ser descrita en pocas palabras como una ronda en la que los músicos giran de modo coordinado, primero hacia la izquierda, y luego alternando en sentido opuesto cada vez que completan la melodía. 
Como advierte Turino (2008), la sincronía física que experimentan los músicos danzantes al seguir un mismo ritmo y producir sonidos, gestos y movimientos corporales en forma coordinada contribuye a potenciar un sentimiento de profunda conexión física y emocional (pp. 2-3, 18). Por este motivo, la actividad musical y coreográfica de los sikuris es central a su propio entendimiento de sí. Gloria, una integrante entusiasta de la escena porteña, me lo explicó de este modo: «Cuando vos estás adentro de la ronda nadie es más importante que el otro [porque] todos aportan [...] y somos uno solo» (julio de 2015).

La amplia difusión de estas prácticas, las asociaciones simbólicas que conllevan y las metas sociales comunes, facilitan un comportamiento relativamente congruente y un sentido de pertenencia social entre los participantes de distintas escenas. Así lo resumió José, un músico bogotano que ha visitado las escenas sikuri de distintos países, donde se ha unido a ensambles locales durante su participación en determinados festivales: «No importa que uno esté en Bolivia, en Perú, en Argentina, en otro país... a cualquier tropa que usted vaya, allá lo reciben, y [por eso] siento que hay una unión en base a tocar el siku [...] Ser sikuri es un estilo de vida total» (septiembre de 2013).

Por otro lado, lejos de estar aisladas, las escenas sikuri se encuentran cada vez más interrelacionadas por conexiones concretas, abstractas y virtuales. Las conexiones concretas incluyen vías como la carretera Panamericana y las nuevas rutas aéreas de bajo costo. Las conexiones abstractas comprenden un gusto compartido por el sikuri y otros tipos de música relacionada con los Andes, la celebración de la técnica de interpretación dialogal de los sikus, un repertorio canónico de melodías, una ideología común y, especialmente, un conjunto de valores solidarios. Finalmente, las conexiones virtuales se basan en redes sociales como YouTube, Facebook y WhatsApp, que les permiten compartir fotos y videos de sus actuaciones, comentar CDs y participar en discusiones sobre los resultados de los concursos, etcétera. Este tipo de conexiones ha potenciado la articulación de individuos, agrupaciones y escenas de una forma sin precedentes.

Argumento que, en virtud de la progresiva intensificación de estas conexiones, el creciente intercambio físico y virtual entre sus agentes, los valores solidarios comunes y el sentimiento de identidad compartida, ha surgido un movimiento sikuri relativamente coherente - lo que no significa que en su interior no existan fricciones entre las diversas posturas ideológicas o estéticas de sus participantes.

A continuación examino algunos de los principales procesos que condicionan la transferencia de conocimientos y prácticas de origen andino a las metrópolis señaladas: la preferencia por determinados paradigmas de autenticidad, 
la influencia de predisposiciones culturales, las elecciones con fines prácticos y las inclinaciones involuntarias.

\section{MÚLTIPLES PARADIGMAS DE AUTENTICIDAD}

Entre los sikuris coexisten diversos ideales de autenticidad que a menudo son fuente de conflicto. Como en el modelo de «campo cultural» formulado por Bourdieu (1979), al interior del movimiento sikuri la autenticidad constituye una forma de capital que proporciona legitimidad a quienes son socialmente reconocidos como sus poseedores. Quienes encabezan la jerarquía de autenticidad sikuri son los músicos «hechos en casa». En el contexto de ciudades cosmopolitas como aquellas donde el movimiento tiene sus principales focos, estas personas son a menudo una minoría (Castelblanco, 2018). La valoración y el respeto por estos individuos es una de las características más sobresalientes del movimiento sikuri, pues confiere un lugar central a las formas de conocimiento alternativo de sectores sociales tradicionalmente excluidos: los indígenas aimara y quechua ${ }^{13}$. Pero además de los músicos «hechos en casa», los sikuris acuden a otras fuentes de información para aprender sobre las prácticas musicales de su interés y replicarlas «con respeto» (profundizaré en esta noción más adelante).

Sin lugar a dudas la fuente predilecta son las experiencias personales o «vivencias» que muchos buscan en pueblos de los Andes durante ceremonias del ciclo vital, y en particular durante las fiestas patronales - los contextos de producción musical por excelencia. Quienes participan en fiestas, y especialmente aquellos que desarrollan vínculos duraderos de amistad y compromiso con músicos indígenas, capitalizan estas experiencias para revestirse de legitimidad dentro del movimiento. Esta forma etnográfica de aprender — basada en la observación participante-, fue inaugurada en la década de 1980 por miembros de distintos conjuntos de sikuris que viajaron de Lima a Puno y es una práctica a la que los sikuris otorgan gran importancia (Turino, 1993, p. 238 y pp.ss ) (ver

13 Cuando hablo de las formas alternativas de conocimiento de los indígenas andinos me refiero a las diversas maneras (interpersonales, kinestésicas y espirituales) a través de las que estos conocen y se relacionan con el mundo (e.g., la lectura de las hojas de coca, la ch'alla o libación ritual e incluso la música y la danza). Estas formas de conocimiento a menudo informan decisiones sobre aspectos fundamentales de la vida diaria y son distintas (aunque no necesariamente incompatibles) con la ciencia y la tradición filosófica del positivismo - formas dominantes difundidas por el colonialismo europeo a través del globo que descartan el reino metafísico o espiritual como fuente de conocimiento. 
Barragán y Mardones, 2018, pp. 547-551; Mardones y Riffo, 2013; Sánchez, 2013, pp. 355-356).

Pero debido a que relativamente pocos sikuris consiguen aplazar sus compromisos y reunir suficiente dinero para viajar hasta lejanos pueblos andinos, la principal fuente de información en que se basan son los testimonios orales de aquellos que sí lo logran. Estos testimonios suelen ser compartidos de manera informal con los integrantes de sus respectivos conjuntos y en instancias públicas más formales que incluyen talleres y ponencias. A través de su traspaso sucesivo, los sikuris a menudo introducen en sus testimonios deslices, errores y nuevas interpretaciones. Mezclando hechos con giros creativos, construyen sus propias narrativas acerca de las circunstancias que rodean la producción musical entre los indígenas andinos, y así dan forma a una actividad musical única (ver Castelblanco, 2019).

Otros recursos a los que los sikuris acuden incluyen videos de fiestas andinas disponibles en YouTube, ciertas monografías de etnomusicología y las notas interiores que acompañan grabaciones etnográficas comerciales. No obstante la importancia de estas últimas, su difícil acceso, el idioma y el lenguaje técnico en que están escritas limitan su impacto dentro del movimiento. Acaso por este motivo los documentos más populares entre los sikuris son aquellos producidos por ellos mismos ${ }^{14}$.

Existe una falange intelectual conformada por sikuris que son a la vez observadores e investigadores de sus propios procesos musicales y sociales. Mientras que plataformas virtuales como Facebook facilitan el intercambio de experiencias y opiniones, entre la cohorte resurgentista los conversatorios, los encuentros y congresos autogestionados constituyen una instancia privilegiada para la fertilización cruzada de ideas y la intensificación de aquellos vínculos que unen a individuos, agrupaciones y escenas, y que — en última instanciacontribuyen a cohesionar el Movimiento a escala internacional. El Congreso Nacional e Internacional del Siku — en Lima - y el Congreso Internacional de Sikuris — en Buenos Aires - son algunos de los encuentros que han producido el mayor impacto en este sentido ${ }^{15}$.

14 Es importante resaltar que muchos sikuris que conozco se muestran apáticos hacia el conocimiento adquirido por vía académica. No solo lo consideran una forma de colonialismo, sino que estiman que es incapaz de abarcar las complejidades de las formas de pensar y vivir de los indígenas andinos. En su lugar privilegian conocimientos basados en la práctica y sus propias suposiciones.

15 Entre otros encuentros cabe destacar en Perú el Encuentro de Sikuris y Sikumorenos Inkarri (2001-2018) y el Congreso Nacional e Internacional del Siku (Lima y Puno, 2011-2015). En Argentina, el Congreso Internacional de Sikuris (2010, 2013, 2019). En Chile, el Encuentro 
Además de dichas instancias, diversos participantes del movimiento han contribuido a la creación de un cuerpo textual en expansión que incluye panfletos, blogs, revistas, volúmenes editados, libros, tesis de grado, grabaciones etnográficas y videodocumentales. A través de estos medios, intelectuales sikuris de diversas nacionalidades y formaciones disciplinares intercambian sus propias teorizaciones sobre la arqueología y organología de instrumentos musicales andinos, reflexiones etnomusicológicas acerca de problemas de interés común como las características que definen los estilos musicales, noticias sobre variantes regionales poco documentadas, las historias de sus escenas, así como perfiles y entrevistas a determinados músicos precursores de sus respectivas escenas o conjuntos ${ }^{16}$.

Al igual que en los procesos de construcción de identidad nacional descritos por Anderson (1993), la diseminación de ideas y símbolos a través de diversos medios incluyendo la imprenta, ha contribuido a la consolidación de una comunidad imaginada de relativa coherencia entre los sikuris. En efecto, un sentimiento de profunda camaradería y horizontalidad - semejante al que experimentan los ciudadanos de una misma nación—, pareciera unir a muchos de quienes participan en este movimiento. Puede que muchos jamás lleguen a conocer a la mayoría de los demás participantes; «no los verán ni oirán siquiera hablar de ellos, pero en la mente de cada uno vive la imagen de su comunión» (Anderson, 1993, p. 23). En palabras de Matías, uno de los participantes de la escena de Buenos Aires: «Los sikuris somos una sola familia: todos somos hermanos» (agosto de 2016). Pero es importante notar que, a diferencia de lo que ocurre en el nacionalismo, la comunidad imaginada de los sikuris resiste las fronteras nacionales en favor de una cierta identidad pan-latinoamericana. En este sentido, Matías advirtió: «las fronteras de los países [son irrelevantes]; son una mentira que nos vendieron para dividirnos, para separarnos. Lo que antes con los incas era un gran ayllu, una gran comunidad, ahora nos estamos dando cuenta que (...) toda Latinoamérica siempre fuimos una sola familia, ¿viste? [...] como un gran ayllu» (agosto de 2016).

de Sikuris Fiesta de los Collasuios (2013). En Colombia, el Encuentro de Músicas y Danzas Comunitarias (2014 y 2015) y el Encuentro de Músicas Comunitarias «Minkha» (2018).

16 En Santiago, por ejemplo, la agrupación Manka Saya editó por espacio de algunos años el Boletín Manka Saya. En Bogotá Óscar Molina, músico, fabricante de instrumentos y cofundador de la Comunidad zampoñas urbanas, edita de modo intermitente la Revista Orígenes. Algunas de las revistas y boletines editados en Lima incluyen Jak'e Aru (Asociación Juvenil Puno), Kunanmanta (Asociación cultural Kunanmanta), Kachkaniraqkun (Conjunto de Zampoñas de San Marcos), Revista Sikuri y Revista Mundo Sikuri (Mallkus 12 de Mayo) — cuyos dos últimos números han reunido colaboraciones de sikuris en Argentina, Bolivia, Brasil, Chile, Colombia, Estados Unidos y Perú. 
La cohesión política de la franja de tierra bajo el control del inca ya había inspirado el enfoque conceptual de artistas de la Nueva Canción chilena (Ríos, 2008, p.156). No cabe duda de que la amplia difusión de esta narrativa entre los sikuris se debe al impacto de la Nueva Canción chilena y otros movimientos afines. Pero los efectos de la analogía son más que retóricos: en incontables ocasiones durante mis jornadas de trabajo de campo yo mismo he sido obsequiado con la hospitalidad y camaradería de desconocidos, quienes no bien se enteran de mi afición por el sikuri, me alojan en su casa con la familiaridad de quien recibe a un pariente.

En síntesis, el de los sikuris es un movimiento transnacional que, pese a su carácter orgánico y a no estar regulado por instituciones centralizadas que lo estructuren, se encuentra cohesionado por un profundo sentimiento de fraternidad.

\section{TOCAR «CON RESPETO»}

Prácticamente todos los sikuris que conozco concuerdan en señalar la importancia de interpretar las tradiciones musicales de los indígenas andinos «con respeto». No obstante la ubicuidad de esta premisa en las discusiones que sostienen durante ensayos y festivales, aquello que entienden por «respeto» rara vez es cabalmente definido. Pienso que, si la mayoría coincide en la importancia de tocar «con respeto», acaso es porque cada quien interpreta lo que esto significa de acuerdo con sus propios objetivos y preferencias.

Conscientes de que la apropiación del patrimonio cultural de pueblos históricamente vulnerados tiene implicaciones éticas de difícil solución, muchos sikuris recurren al respeto como principio mediador de su relación con los músicos indígenas de los Andes. Los sikuris expresan su respeto por los aimara y quechua honrando su resistencia cultural y la tenacidad de haber mantenido vivas estas prácticas musicales durante siglos, pese al silenciamiento que distintas fuerzas han impuesto sobre ellas. Al mismo tiempo, el respeto fundamenta la voluntad de los sikuris de denunciar y acaso enmendar las injusticias históricas de las que estos pueblos han sido víctimas. Ante todo, el respeto comprende el deseo de entender al otro reconociendo y valorando sus diferencias culturales y formas alternativas de conocimiento.

Los sikuris expresan su respeto de diversas formas, la primera de las cuales consiste en reconocer, durante intervenciones públicas, que las tradiciones musicales que interpretan son patrimonio cultural de los indígenas de los Andes (el grado de especificidad de esta atribución varía dependiendo del conocimiento 
individual de los sikuris, y puede llegar hasta la mención de ayllus, parcialidades e incluso individuos específicos). Algunos de los sikuris que viajan hacia los pueblos y aldeas donde este tipo de música ocupa un lugar central, manifiestan su respeto pidiendo permiso a las autoridades y músicos locales para reinterpretar sus tradiciones en sus respectivos contextos metropolitanos ${ }^{17}$. En caso de que tomen fotografías o hagan grabaciones de audio y videos, algunos sikuris expresan su respeto retornando dichos materiales a los músicos locales e, idealmente, estableciendo relaciones de amistad y compromiso. En síntesis, el respeto condiciona los procesos de transferencia cultural que protagonizan los sikuris, pues es el eje moral que articula sus relaciones interculturales y las legitima como éticas.

En lo que a la música respecta, tocar «con respeto» suele ser equiparado a replicar la música de los campesinos indígenas con la mayor fidelidad posible. De hecho, muchos sikuris emplean el concepto de respeto de forma intercambiable con el de autenticidad. Como consecuencia, las innovaciones y desviaciones con respecto a ciertos paradigmas de autenticidad suelen ser interpretadas como faltas de respeto. Por ejemplo, algunos consideran indispensable usar consortes de instrumentos originales e interpretar solo el estilo musical de una región o comunidad específica. Más aún, hay quienes creen esencial seguir los calendarios instrumentales con que los campesinos indígenas marcan los ciclos agrícolas en los Andes centrales y, en consecuencia, durante la temporada de lluvias cambian los sikus por tarkas, moseños u otros aerófonos propios de la estación húmeda (Castelblanco, 2019).

Pero tocar «con respeto» muchas veces implica considerar aspectos que van más allá de lo estrictamente musical. Por ejemplo, muchos sikuris sostienen que es necesario observar ciertas etiquetas sociales que circundan la producción musical

17 Las reacciones de las autoridades y músicos locales son variables. Mientras que algunos otorgan su consentimiento con una mezcla de curiosidad y orgullo, o incluso con la aspiración de promover su agrupación más allá de la región bajo la forma de filiales, otros parecen no comprender por qué personas extranjeras querrían interpretar su música en tierras distantes. Más aún, hay quienes rechazan estas iniciativas por considerar que demuestran falta de integridad. Tal es el caso de una influyente agrupación de Buenos Aires, que por años había interpretado el estilo musical de una región aimara en el norte de Chile con base en las experiencias de campo de algunos de sus miembros. Luego de varias visitas al pueblo, uno de los músicos locales disuadió a los argentinos de seguir interpretando su música en Buenos Aires, demanda que éstos respetaron antes de entrar en un cese de actividades que continúa hasta la fecha (Pérez, 2016, pp. 11-13). Turino (1993) también documenta las reacciones de diferentes integrantes de la legendaria agrupación Qhantati Ururi ante la visita de una comitiva de músicos del Centro Social Conima y su petición de permiso para interpretar su repertorio en Lima a finales de la década de 1980 (pp. 242-246). 
en las aldeas andinas, como la ch'alla (libación ritual de bebidas alcohólicas), el acullico (mascado ritual de hojas de coca) y las muestras físicas de devoción. Muchos también creen imprescindible usar vestimentas originales, e incluso hay quienes optan por restringir la participación femenina en sus conjuntos por temor a desatender la prescripción social que en los ayllus disuade a las mujeres de tocar instrumentos de viento (Vega, 2016).

Significativamente, mientras que muchos sikuris tocan durante marchas cívicas para expresar su solidaridad con la población indígena oprimida u otras causas sociales, existe una vertiente de sikuris que estima inapropiado participar en dichas instancias por considerarlo una falta de respeto. Estos sikuris sostienen que dichos eventos no son compatibles con los contextos familiares, agropecuarios, festivos y religiosos que suelen enmarcar la producción musical en las aldeas andinas. Pese a que muchos de estos sikuris no se oponen a tocar en instancias que son igualmente ajenas a los contextos tradicionales de producción musical, como teatros y escenarios artísticos, sí condenan los usos políticos que algunos dan a la música de sikus. Para ellos, participar en manifestaciones cívicas constituye una desviación con respecto a los propósitos que sus intérpretes originales dan a esta música, lo que compromete su autonomía como expresión popular y acarrea una falta de respeto ${ }^{18}$.

Alex, un integrante de la escena de Santiago, reaccionó así durante una discusión al respecto: «iEl sikuri no se mezcla con política! Tenís que saber bien a dónde sacas esta [música] porque algunos politiqueros [...] [lo] usan para sus fines partidarios $[\ldots]$ hay que saber respetar porque hay [personas] que denigran la esencia tradicional del sikuri tocando en marchas que [no tienen] nada que ver. Si lo que quieren es hacer política, no hay un mensaje político más contundente que darle al sikuri la profundidad y el respeto que se merece» (diciembre de 2017).

Tocar «con respeto» involucra aspectos éticos, musicales, sociales, espirituales y políticos que no es posible condensar en una definición unívoca debido a que acaso existen tantas interpretaciones como sikuris. Es importante señalar, no obstante, que estas muestras de respeto pocas veces son dirigidas a los cam-

18 Una situación emblemática ocurrió en Lima a mediados de la década de 1980, cuando ciertos conjuntos de sikuris universitarios fueron cooptados por células guerrilleras de Sendero Luminoso. Periodistas denunciaron este hecho y diseminaron asociaciones nocivas entre los conjuntos de sikuris y esta agrupación insurgente, con lo cual comprometieron la seguridad y autonomía de la escena local. Actualmente parte importante de esta rechaza que los sikuris participen en marchas políticas, en especial aquellas con connotaciones partidistas (Acevedo, 2003, pp. 65-66, 86-88; Sánchez, 2013, pp. 263-286). 
pesinos indígenas y que sus principales destinatarios suelen ser otros sikuris. En breve, muchas veces los sikuris recurren a la noción de respeto como dispositivo retórico para defender su propia legitimidad en tanto intérpretes de las tradiciones musicales de los aimara y quechua, más que como expresión de su obligación moral hacia estos.

Siguiendo la teoría de Bourdieu (1979) sobre las formas simbólicas del capital, las diversas manifestaciones de respeto pueden ser interpretadas como mecanismos a través de los que los sikuris ganan prestigio y se posicionan, primero dentro de sus respectivas escenas, y luego dentro del campo cultural sikuri en general. Así, los sikuris demuestran su capital cultural identificando y replicando las peculiaridades estilísticas de distintas regiones, o practicando con desenvoltura etiquetas rituales andinas — como el acullico o la libación. De manera análoga, prueban su capital social estableciendo relaciones de amistad con músicos indígenas de regiones paradigmáticas y — de manera significativaasegurándose de que otros sikuris lo sepan.

En conclusión, puede decirse que la noción de «respeto» comprende al menos dos dimensiones. La primera está compuesta por las muestras de este tipo destinadas a los intérpretes originales de las tradiciones musicales en cuanto tienen el sentido de obligaciones morales. La segunda, más habitual, tiene que ver con las demostraciones de distintas formas de capital que los sikuris hacen a sus pares dentro del campo cultural sikuri. Mediante estas demostraciones, los sikuris reclaman legitimidad como poseedores del conocimiento y la habilidad requerida para replicar prácticas andinas de acuerdo con los valores de autenticidad que, como señalé, varían sustancialmente entre individuos, agrupaciones y cohortes.

\section{CONCLUSIONES}

El sikuri es un mundo apasionante al que cualquier persona puede entrar para unirse a la ronda y hacer música, y donde puede sentirse valorada y esencial al margen de sus habilidades musicales. Se trata de un mundo que promueve un sentido de comunidad e interacciones positivas entre sus miembros, y en el cual estos descubren alternativas para interpretar y conducir su vida con base en un conjunto de valores solidarios.

Cuando los sikuris usan de forma colectiva sus instrumentos y danzas para expresar sus inconformidades y solidaridades, abren espacios políticos y establecen su poder como ciudadanos. Más allá de su participación en movilizaciones cívicas, las actividades de los sikuris constituyen un ejercicio de ciudadanía en 
tanto afirman la importancia de las culturas indígenas andinas y abren discusiones necesarias sobre problemas asociados a la xenofobia, el racismo y el colonialismo interno. Los sikuris no solo interpelan las narrativas hegemónicas de nación y raza sino que - al adoptar ciertos elementos culturales el acullico y los discursos sobre la dualidad complementaria—, promueven la valoración de las formas de conocimiento de sectores sociales tradicionalmente excluidos (i.e., los campesinos indígenas de los Andes). Más aún, el movimiento sikuri constituye una instancia privilegiada para revertir el flujo dominante de conocimientos — que suelen ser producidos en centros metropolitanos por agentes hegemónicos, y más tarde diseminados en la periferia mediante aparatos institucionales como la escuela. En efecto, junto con prácticas musicales de origen indígena, muchos sikuris también suelen celebrar en el contexto de sus respectivas ciudades una variedad de conocimientos indígenas como los relacionados con la conceptualización de las estaciones y los ciclos agrícolas, la relación con los seres más-que-humanos y la manipulación del clima, por nombrar solo algunos.

De este modo, los sikuris no solo critican y protestan contra las estructuras sociales hegemónicas, sino que — acaso más importante - inspiran estilos de vida alternativos al prefigurar una visión de la sociedad que anhelan. Cuando mi amiga resumió su experiencia como sikuri diciendo «no somos nadie sin el otro», dejó en claro la importancia que para los sikuris tienen los habitantes indígenas de los Andes en tanto modelo de autenticidad musical, identitaria, e incluso moral. El conjunto de prácticas, símbolos y valores en que los sikuris se inspiran, se manifiesta de manera ejemplar en la ronda de los sikuris, donde las personas encarnan una entidad colectiva que por momentos trasciende su individualidad.

Así, la participación en un conjunto de sikuris puede inspirar transformaciones en los hábitos de pensamiento y práctica de sus miembros. Aun cuando el impacto social que tienen las actividades de los sikuris pueda parecer leve, considero que su articulación continental como Movimiento potencialmente tiene la capacidad de generar transformaciones profundas en la identidad, la cultura y la sociedad latinoamericanas. Estas transformaciones son, por el momento, un proceso en desarrollo. 


\section{REFERENCIAS}

Acevedo, Saúl (2003). Los sikuris de San Marcos: historia del Conjunto de Zampoñas de San Marcos. Lima: Alter-Nativa.

Anderson, Benedict (1993). Comunidades imaginadas. Reflexiones sobre el origen y la difusión del nacionalismo. México: Fondo de Cultura Económica.

Barragán, Fernando y Pablo Mardones (2015). Che sikuri: la expresión del siku en el contexto porteño. Su rol en las dinámicas de reproducción aymara-quechuas y su constitución como parte de la identidad cultural de Buenos Aires [inédito].

Barragán, Fernando y Pablo Mardones (2018). Marcar las diferencias: construcciones sonoro-estilísticas de las bandas de sikuris de Buenos Aires. En Carlos Sánchez (ed.), Música y sonidos en el mundo andino: flautas de Pan, zampoñas, antaras, sikus y ayarachis (pp. 535-554). Lima: Universidad Nacional Mayor de San Marcos.

Baumann, Max Peter (1982). Music in the Andean Highlands. En Bolivien: Musik im Andenhochland, grabado por Max Peter Baumann, 25-39 Berlín: Museum für Völkerkunde. [LP].

Baumann, Max Peter (1996). Andean Music, Symbolic Dualism and Cosmology. En Max Peter Baumann (ed.), Cosmología y música en los Andes (pp. 15-66). Madrid: Vervuert.

Bourdieu, Pierre (1979). La distinction: critique sociale du jugement. París: Minuit.

Castelblanco, Daniel (2014). Soplando sikus más allá del Titicaca: conjuntos de sikuris como islas del archipiélago cultural transandino en Buenos Aires, Santiago y Bogotá. Revista de Crítica Literaria Latinoamericana, 80(2), 265-282.

Castelblanco, Daniel (2018). Sikuris altiplánicos, regionales y metropolitanos: revisión de un esquema de clasificación. En Carlos Sánchez (ed.), Música y sonidos en el mundo andino: flautas de Pan, zampoñas, antaras, sikus y ayarachis (pp. 485-510). Lima: Universidad Nacional Mayor de San Marcos.

Castelblanco, Daniel (2019). Del ayllu a la metrópoli: transformación de los usos y significados de la música aymara al interior de una comunidad transnacional de resurgentistas de la música andina. Latin American Music Review / Revista de Música Latinoamericana, 40(2), 105-137. https://doi.org/10.7560/LAMR40201

Céspedes, Gilka Wara (1984). New Currents in «Música Folklórica» in La Paz, Bolivia. Latin American Music Review / Revista de Música Latinoamericana, 5(2), 217242. https://doi.org/10.2307/780073

De la Cadena, Marisol (1990). De utopías y contrahegemonías: el proceso de la cultura popular. Revista Andina, 15, 65-76. 
Dunphy, Kim (2018). Theorising Arts Participation as a Social Change Mechanism. En Brydie-Leigh Bartleet y Lee Higgins (eds.), The Oxford Handbook of Community Music (pp. 301-321). Oxford: Oxford University Press. https://doi.org/10.1093/ oxfordhb/9780190219505.013.16

Gavazzo, Natalia (2017). Sikuris en Buenos Aires: la música como herramienta de participación de los migrantes bolivianos y sus hijos. En Marcos González (ed.), Ceremoniales festivos: Argentina, Bolivia, Brasil, Colombia y México (pp. 37-54). Bogotá: Intercultura Colombia.

Hill, Juniper y Caroline Bithell (2014). An Introduction to Music Revival as Concept, Cultural Process, and Medium of Change. En Caroline Bithell y Juniper Hill (eds.), The Oxford Handbook of Music Revival (pp. 3-42). Oxford: Oxford University Press. https://doi.org/10.1093/oxfordhb/9780199765034.013.019

Ibarra, Miguel Ángel (2012). El siku en Santiago de Chile. Boletín Haylli, 19, 8-9.

Livingston, Tamara (2014). An Expanded Theory for Revivals as Cosmopolitan Participatory Music Making. En Caroline Bithell y Juniper Hill (eds.), The Oxford Handbook of Music Revival (pp. 60-69). Oxford: Oxford University Press. https://doi.org/10.1093/oxfordhb/9780199765034.013.018

Mardones, Pablo y Rodrigo Riffo (2013). Noble corazón: alma de acero, sangre rebelde. YouTube, ALPACA producciones. Recuperado de https://www.youtube.com/ watch?v=KsSCz7L28BM

Mora, Gerardo (ed.) (2012). Lakitas en Arica: zampoñas, sopladores y ritmos en el Norte de Chile. Santiago: Azapa.

Mendívil, Julio y Christian Spencer (2016). Epilogue: Reconsidering Music Scenes from a Latin American Perspective. En Julio Mendívil y Christian Spencer (eds.), Made in Latin America (pp. 160-164). Nueva York: Routledge. https:// doi.org/10.4324/9781315880549

Murra, John (1972). Formaciones ecológicas y políticas del mundo andino. Lima: Instituto de Estudios Peruanos.

Pedro, Josep, Ruth Piquer y Fernán del Val (2018). Repensar las escenas musicales contemporáneas: genealogía, límites y aperturas. Cuadernos de Etnomusicología, 12, 63-88.

Pérez, Lautaro (2016). Tensiones entre concepciones musicales en la práctica del siku en Buenos Aires: el caso de la Banda de Sikuris de IMPA [inédito].

Peterson, Richard y Andy Bennett (2004). Introducing Music Scenes. En Andy Bennett y Richard Peterson (eds.), Music Scenes: Local, Translocal and Virtual (pp. 1-15). Nashville: Vanderbilt University Press. https://doi.org/10.2307/j.ctv17vf74v.5 
Podhajcer, Adil (2011). El diálogo musical andino: emoción y creencias en la creatividad de conjuntos de «música andina» de Buenos Aires (Argentina) y Puno (Perú). Latin American Music Review / Revista de Música Latinoamericana, 32(2), 269-293. https://doi.org/10.1353/lat.2011.0015

Podhajcer, Adil (2015). Sembrando un cuerpo nuevo: performance e interconexión en prácticas musicales «andinas» de Buenos Aires. Revista Musical Chilena, 223(1), 47-65. https://doi.org/10.4067/S0716-27902015000100004

Poole, Deborah (1992). Antropología e historia andinas en los EE.UU.: buscando un reencuentro. Revista Andina, 10(1), 209-245.

Ríos, Fernando (2008). La Flûte Indienne: The Early History of Andean Popular Folkloric Music in France and its Impact on Nueva Canción. Latin American Music Review / Revista de Música Latinoamericana, 29(2), 145-181.

Sánchez, Carlos (2013). La flauta de Pan andina: los grupos de sikuris metropolitanos. Lima: Universidad Nacional Mayor de San Marcos.

Sinti, Nirvana (2017). Llegó a Bogotá sin migrantes: génesis de la práctica musical sikuri en la capital colombiana. Revista Mundo Sikuri, 2, 83-87.

Taypi Aru, Compañía de Investigación y Danzas Andinas (ed.). (2011). Santiago jacha marka: danzas, cosmovision, festividades y acción política en el espacio urbano. Santiago: Quimantú.

Turino, Thomas (1993). Moving Away from Silence: Music of the Peruvian Altiplano and the Experience of Urban Migration. Chicago: University of Chicago Press. https://doi.org/10.7208/chicago/9780226816951.001.0001

Turino, Thomas (2008). Music as Social Life: The Politics of Participation. Chicago: University of Chicago Press. https://doi.org/10.1093/acprof: oso/9780199393749.003.0015

Turino, Thomas (2016). Music, Social Change, and Alternative Forms of Citizenship. En David Elliott, Marissa Silverman y Wayne Bowman (eds.), Artistic Citizenship: Artistry, Social Responsibility, and Ethical Praxis (pp. 297-312). Oxford: Oxford University Press. https://doi.org/ 10.1093/acprof:oso/9780199393749.003.0015

Turino, Thomas (2018). Participatory Performance and the Authenticity of Place in Old-time Music. En Suzel Reily y Katherine Brucher (eds.), The Routledge Companion to the Study of Local Musicking (pp. 17-28). Nueva York: Routledge. https://doi.org/10.4324/9781315687353-3

Van Dam, Anke y Ton Salman (2003). Andean Transversality: Identity between Fixation and Flow. En Annelies Zoomers y Ton Salman (eds.), Imaging the Andes: Shifting Margins of a Marginal World (pp. 15-39). Amsterdam: Aksant. 
Vega, María Alejandra (2016). Rebuilding the Pre-Hispanic Religiosity in an Urban Area: The Case of the Urban Sikus Bands in Buenos Aires. Sociology and Anthropology 12(4), 1066-1078. https://doi.org/10.13189/sa.2016.041205 